Open Access

\title{
Erratum to: Left ventricular function during porcine-resuscitated septic shock with pre- existing atherosclerosis
}

Benedikt L. Nußbaum ${ }^{1,2^{*}}$, Oscar McCook ${ }^{2}$, Clair Hartmann ${ }^{1,2}$, José Matallo², Martin Wepler ${ }^{1,2}$, Elena Antonucci ${ }^{3}$, Miriam Kalbitz ${ }^{4}$, Markus Huber-Lang ${ }^{4}$, Michael Georgieff', Enrico Calzia ${ }^{2}$, Peter Radermacher ${ }^{2}$ and Sebastian Hafner ${ }^{1,2}$

* Correspondence: benedikt. nussbaum@uni-ulm.de

${ }^{1}$ Klinik für Anästhesiologie, Universitätsklinik Ulm, Ulm, Germany

${ }^{2}$ Institut für Anästhesiologische Pathophysiologie und Verfahrensentwicklung,

Universitätsklinik UIm, Helmholtzstraße 8/1, Ulm 89081 Germany

Full list of author information is available at the end of the article

\section{Erratum}

Unfortunately, after publication of this article [1], it was noticed that the 'Statistical analysis' section contained an error. The first sentence should read, "All data are expressed as median (IQ range)" to remain congruous with data displayed in tables. The original article has been updated to reflect this.

\section{Author details \\ ${ }^{1}$ Klinik für Anästhesiologie, Universitätsklinik Ulm, Ulm, Germany. ${ }^{2}$ Institut für Anästhesiologische Pathophysiologie und Verfahrensentwicklung, Universitätsklinik UIm, Helmholtzstraße 8/1, Ulm 89081, Germany. ${ }^{3}$ Department of Surgical Sciences and Integrated Diagnostics, IRCCS San Martino IST, University of Genova, Genova, Italy. ${ }^{4}$ Klinik für Unfall-, Hand-, Plastische- und Wiederherstellungschirurgie, Universitätsklinik Ulm, Ulm, Germany}

Received: 21 June 2016 Accepted: 22 June 2016

Published online: 28 June 2016

\section{Reference}

1. Nußbaum BL, McCook O, Hartmann C, Matallo J, Wepler M, Antonucci E, Kalbitz M, Huber-Lang M, Georgieff M Calzia E, Radermacher P, Hafner S (2016) Left ventricular function during porcine-resuscitated septic shock with pre-existing atherosclerosis. Intensive Care Med Exp 4:14. doi:10.1186/s40635-016-0089-y

\section{Springer Open}

( 2016 The Author(s). Open Access This article is distributed under the terms of the Creative Commons Attribution 4.0 International License (http://creativecommons.org/licenses/by/4.0/, which permits unrestricted use, distribution, and reproduction in any medium, provided you give appropriate credit to the original author(s) and the source, provide a link to the Creative Commons license, and indicate if changes were made. 